Pathway \#1, Techniques/Methods to Minimize/Eliminate Variability and Increase Paper Machine Efficiency

\author{
QUARTERLY REPORT
}

Project \# DE-FC36-99G010416

\title{
Improving Paper Machine \\ Efficiency Through On-Line Control of \\ Stock Delivery, Headbox and Forming Hydrodynamics
}

\author{
Principal Investigator: Cyrus K. Aidun \\ Institute of Paper Science and Technology \\ Atlanta, GA 30318
}

Phone: 404-894-6645

Fax: 404-894-1496

e-mail: cyrus.aidun@ipst.edu

February 2000 


\section{DISCLAIMER}

This report was prepared as an account of work sponsored by an agency of the United States Government. Neither the United States Government nor any agency thereof, nor any of their employees, make any warranty, express or implied, or assumes any legal liability or responsibility for the accuracy, completeness, or usefulness of any information, apparatus, product, or process disclosed, or represents that its use would not infringe privately owned rights. Reference herein to any specific commercial product, process, or service by trade name, trademark, manufacturer, or otherwise does not necessarily constitute or imply its endorsement, recommendation, or favoring by the United States Government or any agency thereof. The views and opinions of authors expressed herein do not necessarily state or reflect those of the United States Government or any agency thereof. 


\section{DISCLAIMER}

Portions of this document may be illegible in electronic image products. Images are produced from the best available original document. 
1. Status of the Technical Scope of Work

The microforming unit is being designed for a Type- $\mathrm{W}$ headbox. The pilot trials are planned for June of 2000 at Ravensburg, Germany.

Design of the on-line electronic control system started in January of this year. The application of 'smart material' in the control system has been analyzed and the practical aspects of these techniques have been evaluated during the past quarter. A promising technique has been selected for evaluation in the lab during the next six months.

2. Level of Completion:

The remaining task in the microforming system application is to design the static microforming system for a Type-W headbox in time for pilot trials during June of this year.

The design and fabrication of the on-line control systems has started with the goal of laboratory demonstration of this system in a headbox by the end of this year. The computational fluid dynamics analysis has been partly completed as the preliminary studies and evaluation of the methods.

\section{Significant Program/Project Tests}

The image analysis software for rapid measurement of fiber orientation in the laboratory headbox has been completed. Preliminary experiments for evaluation of the laboratory headbox and the flow loop constructed during the last six months have been completed. The diagnostics equipment including high-speed imaging and the Laser-Doppler Anemometer has been evaluated with the conventional headbox system.

4. Upcoming conferences

There are no papers planned for upcoming conferences at this time.

\section{Variances to cost or schedule}

It has been proposed and accepted by the OIT Office in Washington to use part of the funding for the second year $(\sim 75 \mathrm{~K})$ for partial funding of the AF\&PA project for commercial application of a microforming retrofit to the Escher Wyss headbox in Florence, SC. Per Ms. Valri Robinson, the OIT office has agreed to add the $\$ 75 \mathrm{~K}$ funding to this project above the previously funded budget for the fourth year of the project. Therefore, with this additional task, some of the other tasks will be postponed for a quarter, as reflected in the next section. The remaining part of the project is on schedule. 
Summary of the additional task:

IPST has a major project with the Containerboard Group (CG) of AF\&PA concerned with the Hydrodynamics of Forming directed by the current project PI. The CG project is a commercial demonstration of the 'swirl-tube' technology invented by Aidun and patented by IPST. Pilot trials in an AF\&PA member company's pilot plant has been successfully completed in addition to the Voith Sulzer pilot plant in Germany at commercial speeds. There have been no glitches thus far and the potential benefits appear to be greater than first anticipated. The next step is a full-scale commercial trial on a actual paper machine. The commercial trial, scheduled for first week of January 00, requires the manufacturing of a new full size tube block and tubes for the commercial machine. The total cost has been over $\$ 550 \mathrm{~K}$ most of which has been funded by AF\&PA and the supplier companies involved with the project. An additional $\$ 75 \mathrm{~K}$ is required to complete the fabrication of the commercial tube block.

By co-funding this project, DOE-OIT will be associated with a full-blown commercial trial that is expected to be a complete success. The AF\&PA Containerboard member companies have welcomed the additional funding by DOE-OIT to expedite the project since they are anxious to have the technology available as soon as possible. And the results of the January trial would be known in a matter of months. The CG support of this project over the past two years is over $\$ 470 \mathrm{~K}$. By adding the in-kind contributions from the supplier companies to this amount, the industry-government cost share ratio would be very favorable. There are plans for $\mathrm{CG}$ to continue the project through board testing and box making.

The tasks already planned in this project builds on the commercial trial added to the project, so the success of the January trials will considerably elevate the significance of the current DOE-OIT project in the eyes of the industry.

6. Updated Task Schedule for the Project:

The added tasks to the project will only influence the schedule of tasks for the on-line control system. The Schedule for the Development of the Static Microforming System remains unchanged. 
Schedule for the Development of the Static Microforming System:

\begin{tabular}{|c|c|c|c|c|c|c|c|c|c|c|c|c|c|c|c|c|}
\hline \multirow{2}{*}{$\begin{array}{ll}\text { TASKS } & \text { Quarters } \rightarrow\end{array}$} & \multicolumn{4}{|c|}{ Year 1} & \multicolumn{4}{|c|}{ Year 2} & \multicolumn{4}{|c|}{ Year 3} & \multicolumn{4}{|c|}{ Year 4} \\
\hline & $\pi$ & 2 & 3 & 4 & $\pi$ & 2 & 3 & 4 & $T$ & 2 & 3 & 4 & $T$ & 2 & 3 & 4 \\
\hline \multicolumn{17}{|l|}{ Phase 1-CFD Analysis \& Exp. Verification } \\
\hline Design Retrofit Concept & $\sqrt{1}$ & & & & & & & & & & & & & & & \\
\hline CFD Evaluation of Concept & $\sqrt{1}$ & $\sqrt{ }$ & & $\sqrt{ }$ & & & & $\sqrt{1}$ & & & & & & & & \\
\hline LDA Measurements and CFD Verification & & & & & $\sqrt{1}$ & $\sqrt{1}$ & & $\sqrt{1}$ & & & & & & & & \\
\hline & & & & & & & & & & & & & & & & \\
\hline \multicolumn{17}{|l|}{ Phase II - Pilot Trials: } \\
\hline Retrofit Concept for Pilot Trials & & & $\sqrt{ }$ & $\sqrt{ }$ & $\sqrt{ }$ & & & & & & $\sqrt{ }$ & $\sqrt{1}$ & $\sqrt{1}$ & & & \\
\hline Laboratory Evaluation & & & & $\sqrt{ }$ & $\sqrt{ }$ & & & & & & & $\sqrt{1}$ & $\sqrt{ }$ & & & \\
\hline Pilot Machine Installation/Trials & & & & & $\sqrt{1}$ & $\sqrt{ }$ & $\sqrt{ }$ & & & & & & $\sqrt{ }$ & $\sqrt{ }$ & $\sqrt{ }$ & \\
\hline & & & & & & & & & & & & & & & & \\
\hline \multicolumn{17}{|l|}{ Phase III - Commercial Trials: } \\
\hline Commercial Retrofit Design & & & & & & & $\sqrt{ }$ & $\sqrt{ }$ & & & $\sqrt{ }$ & $\sqrt{1}$ & & & & \\
\hline Laboratory Evaluation & & & & & $\sqrt{1}$ & $\sqrt{1}$ & & $\sqrt{ }$ & $\sqrt{ }$ & & & & $\sqrt{ }$ & & & \\
\hline Fabrication & & & & & & $\sqrt{ }$ & $\sqrt{ }$ & & $\sqrt{1}$ & $\sqrt{ }$ & & & $\sqrt{1}$ & $\sqrt{ }$ & & \\
\hline Machine Installation/Trials & & & & & & & $\sqrt{ }$ & $\sqrt{ }$ & & $\sqrt{1}$ & $\sqrt{ }$ & $\sqrt{1}$ & & $\sqrt{ }$ & $\sqrt{ }$ & $\sqrt{ }$ \\
\hline Commercial Trial/Escher-Wyss HB (\$75K) & & & & & & $\sqrt{ }$ & $\sqrt{ }$ & $\sqrt{1}$ & & & & & & & & \\
\hline & & & & & & & & & & & & & & & & \\
\hline Report at each milestone & & $\sqrt{ }$ & & $\sqrt{ }$ & & $\sqrt{ }$ & & $\sqrt{1}$ & & $\sqrt{1}$ & & $\sqrt{1}$ & & $\sqrt{ }$ & & $\sqrt{ }$ \\
\hline
\end{tabular}


Schedule for the Development of the On-Line Field Control System:

\begin{tabular}{|c|c|c|c|c|c|c|c|c|c|c|c|c|c|c|c|c|}
\hline \multirow{2}{*}{$\begin{array}{ll}\text { TASKS } & \text { Quarters } \rightarrow\end{array}$} & \multicolumn{4}{|c|}{ Year 1} & \multicolumn{4}{|c|}{ Year 2} & \multicolumn{4}{|c|}{ Year 3} & \multicolumn{4}{|c|}{ Year 4} \\
\hline & 1 & 2 & 3 & 4 & $T$ & 2 & 3 & 4 & T1 & 2 & 3 & 4 & 1 & 2 & 3 & 4 \\
\hline \multicolumn{17}{|l|}{ Phase 1- Laboratory Experiments: } \\
\hline Design Tubes for the Tube Bundle & & & & $\sqrt{ }$ & $\sqrt{ }$ & & & & & & & & & & & \\
\hline System Installation/Optimization & & & & & & $\sqrt{ }$ & $\sqrt{ }$ & $\sqrt{ }$ & & & & & & & & \\
\hline CFD Characterization & & & & & & $\sqrt{1}$ & $\sqrt{1}$ & $\sqrt{1}$ & $\sqrt{ }$ & & & & & & & \\
\hline \multicolumn{17}{|l|}{ Laser-Doppler Turbulence Characterization } \\
\hline & & & & & & & & & & & & & & & & \\
\hline \multicolumn{17}{|l|}{ Phase II-Pilot Trials: } \\
\hline Retrofit Concept for Pilot Trials & & & & & & & & & $\sqrt{1}$ & $\sqrt{ }$ & & & & & & \\
\hline Laboratory Evaluation & & & & & & & & & & $\sqrt{1}$ & $\sqrt{ }$ & & & & & \\
\hline Pilot Machine Installation/Trials & & & & & & & & & & & $\sqrt{ }$ & $\sqrt{ }$ & $\sqrt{ }$ & & & \\
\hline & & & & & & & & & & & & & & & & \\
\hline \multicolumn{17}{|l|}{ Phase III-Commercial Trials: } \\
\hline Commercial Retrofit Design & & & & & & & & & & & & $\sqrt{1}$ & $\sqrt{ }$ & & & \\
\hline Laboratory Evaluation of Rapid Prototype & & & & & & & & & & & & & $\sqrt{ }$ & $\sqrt{ }$ & & \\
\hline Fabrication of the Actual System & & & & & & & & & & & & & & $\sqrt{ }$ & $\sqrt{ }$ & \\
\hline Machine Installation/Trials/Optimization & & & & & & & & & & & & & & & $\sqrt{ }$ & $\sqrt{ }$ \\
\hline & & & & & & & & & & & & & & & & \\
\hline Report at each milestone & & & & & & & & $\sqrt{ }$ & & & & $\sqrt{ }$ & & & & $\sqrt{ }$ \\
\hline
\end{tabular}

